\title{
Bacia hidrográfica e a confecção de recursos didáticos por alunos do ensino fundamental em Sergipe
}

\author{
Watershed and the creation of didactic resources by elementary \\ school students in Sergipe
}

Galileu Ribeiro Santos', Andressa Sales Coelho"

\begin{abstract}
RESUMO
O estudo das bacias hidrográficas possui grande relevância para o meio ambiente porque promove a elaboração de planos que objetivem o equilíbrio do funcionamento hídrico e da manutenção dos ecossistemas. A inserção dessa temática dentro da escola reforça uma relação mais harmônica entre a sociedade e o uso dos recursos hídricos. O presente trabalho teve como objetivo construir três recursos didáticos (jogo da memória, maquete e cartilha educativa) dentro do ambiente escolar, para apresentar informações sobre a importância da conservação ambiental da Bacia Costeira do Sapucaia, no Estado de Sergipe, de maneira lúdica e interativa. O diálogo com os discentes na confecção dos recursos didáticos evidenciou a escassez de conhecimento sobre bacias hidrográficas e as atividades permitiram a construção desse conhecimento, considerando-se os diversos estilos de aprendizagem.
\end{abstract}

Palavras-chave: Bacia Costeira do Sapucaia; Educação ambiental; Recursos didáticos

\section{ABSTRACT}

The study of watershed has great relevance for the environment because it promotes the preparation of plans that aim at the balance of water functioning and the maintenance of ecosystems. The inclusion of this theme within the school reinforces a more harmonic relation between society and the use of hydric resources. The aim of this paper is to develop three teaching resources (memory game, scale model and educational booklet) within the school environment, with the intention of informing about the importance of environmental conservation of the Bacia Costeira do Sapucaia in the state of Sergipe, in a playful and interactive manner. The dialogue with students in the production of teaching resources showed the lack of knowledge about watershed and the activities allowed the construction of this knowledge considering the different learning styles.

Keywords: Bacia Costeira do Sapucaia; Environmental Education; Didactic resources

\section{INTRODUÇÃO}

'Mestre em Saúde e Ambiente. Laboratório de Biologia Tropical, Instituto de Tecnologia e Pesquisa, Universidade Tiradentes. Email: galileuribeiro@outlook.com ORCID: https://orcid.org/0000-0003-2417-7217

"Doutora em Ecologia e Recursos Naturais. Laboratório de Biologia Tropical, Instituto de Tecnologia e Pesquisa, Universidade Tiradentes. E-mail: andscoelho@yahoo.com.br ORCID: https://orcid.org/0000-0001-9042-682X 
As bacias hidrográficas são áreas da superfície terrestre onde ocorre o processo natural de captação e drenagem da água da chuva (POSTEL; THOMPSON, 2005). Parte da água infiltra no solo fica armazenada no subsolo e, posteriormente, pode emergir na superfície, dando origem a uma nascente que formará novos cursos de água (rios, riachos, ribeiros, entre outros). A água que não infiltra no solo escoa até os cursos de água, porém existem também outros caminhos como o escoamento subsuperficial, o processo de evapotranspiração ou até mesmo a retenção da água pela vegetação (TEODORO et al., 2007; GÓIS; MENDES, 2013).

A área de uma bacia hidrográfica é formada por um limite superior, também conhecido como divisor de águas, visto que divide bacias adjacentes, o qual é seguido por um trecho médio, com acentuada declividade, onde os cursos de água são drenados até o rio principal. Nas delimitações mais inferiores, o rio principal segue até sua foz, onde deságua no mar (TUCCl; MENDES, 2006; TUNDISI, 2013).

A importância ambiental das bacias hidrográficas está relacionada à proteção e à conservação das nascentes e matas ciliares, que são fundamentais para a manutenção do equilíbrio e funcionamento hídrico, bem como para a manutenção dos ecossistemas (MACHADO et al., 2018). A proteção e conservação das nascentes asseguram uma boa vazão e qualidade da água, essenciais para o consumo humano e agrícola (BARRETO et al., 2010).

No Código Florestal (Lei $n^{\circ} 12.651$, alterada pela Lei $n^{\circ} 12.727$ ), em seu Capítulo II - Art. 4º, institui, como Área de Preservação Permanente (APP), as “áreas no entorno das nascentes e dos olhos d’água perenes, qualquer que seja sua situação topográfica, no raio mínimo de 50 (cinquenta) metros" (BRASIL, 2012a). As APPs referentes a matas ciliares são caracterizadas como faixas de vegetação que ocorrem nas margens dos cursos de água, compostas por uma diversidade de solos, fauna e flora (CASTRO et al., 2012). Essa vegetação é indispensável na proteção do solo no entorno dos cursos de água, na regulação 
do microclima e no abrigo para uma grande diversidade de espécies da fauna, além de funcionar como corredor ecológico, interligando fragmentos florestais e facilitando o trânsito de animais (BALBINOT et al., 2008; CASTRO et al., 2012).

O Brasil possui 12 regiões hidrográficas (Amazonas, Atlântico Leste, Atlântico Nordeste Ocidental, Atlântico Nordeste Oriental, Atlântico Sudeste, Atlântico Sul, Paraguai, Paraná, Parnaíba, São Francisco, Tocantins-Araguaia e Uruguai) e detém cerca de $12 \%$ de toda a água doce do planeta $\left(1.488 .000 \mathrm{~m}^{3} / \mathrm{s}\right)$, utilizada para uso animal, industrial, rural, urbano e irrigação (TELLES, 2013; TUNDISI, 2013). Diante do exposto, a importância das bacias hidrográficas para o meio ambiente é inquestionável, apesar de sofrerem com impactos constantes como retirada da mata ciliar, poluição das águas, introdução de fauna e flora exóticas, entre outros (PEÇANHA; FREITAS, 2013).

Segundo Sodré (2012), as diversas ações antrópicas que resultam na contaminação dos corpos hídricos podem ser caracterizadas de duas formas: Fontes de Poluição Pontuais, caracterizadas como aquelas passíveis de identificação e diagnóstico (ex.: esgotos domésticos e industriais); e Fontes Difusas ou Não Pontuais, cuja origem não é facilmente identificada (ex.: agrotóxicos e fertilizantes aplicados no solo), o que dificulta a implementação de ações de controle ou punição.

A partir da relevância das bacias hidrográficas para o meio ambiente e do seu atual cenário de degradação, ações no âmbito da Educação Ambiental (EA) são fundamentais. Segundo Santos; Santos (2016), a inserção da EA no ambiente escolar contribui para a sensibilização acerca da importância de uma relação harmônica entre o ser humano e o meio ambiente, assegurando o uso sustentável dos recursos naturais para suprir as necessidades humanas e manter a qualidade de vida.

Em 1999, foi criada a Lei n 9795, que instituiu a Política Nacional de Educação Ambiental (PNEA), a qual é definida da seguinte forma: 
Art. $1^{\circ}$ Entendem-se por educação ambiental os processos por meio dos quais o indivíduo e a coletividade constroem valores sociais, conhecimentos, habilidades, atitudes e competências voltadas para a conservação do meio ambiente, bem de uso comum do povo, essencial à sadia qualidade de vida e sua sustentabilidade.

Art. $2^{\circ} \mathrm{A}$ educação ambiental é um componente essencial e permanente da educação nacional, devendo estar presente, de forma articulada, em todos os níveis e modalidades do processo educativo, em caráter formal e não-formal (BRASIL, 1999).

A PNEA estabelece que a EA no âmbito escolar deverá se fazer presente em todos os níveis de ensino, não como disciplina específica no currículo de ensino, mas como tema transversal, envolvendo todos os professores (BRASIL, 1999). De acordo com o Artigo $8^{\circ}$ das Diretrizes Curriculares Nacionais para a Educação Ambiental:

A Educação Ambiental, respeitando a autonomia da dinâmica escolar e acadêmica, deve ser desenvolvida como uma prática educativa integrada e interdisciplinar, contínua e permanente em todas as fases, etapas, níveis e modalidades, não devendo, como regra, ser implantada como disciplina ou componente curricular específico (BRASIL, 2012b).

Logo, a introdução da EA no espaço escolar é assegurada por lei, uma vez que é nesse ambiente onde ocorrem as primeiras dinâmicas de socialização do ser humano e onde os conhecimentos reunidos ao longo da história da humanidade são construídos (KLEIN; PÁTARO, 2008; OLIVEIRA et al., 2013). A escola é um ambiente heterogêneo, que reúne indivíduos com diferentes características culturais, religiosas ou de gênero e essa diversidade está presente, também, na forma de absorver os assuntos trabalhados em sala de aula (LIMA, 2012).

Segundo Oliveira et al. (2016), cada aluno possui uma ou mais formas de aprendizagem. O estilo VAK (Visual, Auditory e Kinesthetic) é considerado um clássico por servir de base para formulação de novos modelos de estilos de aprendizagem. O VAK propõe a existência de três canais de conhecimento representados pelo sentido: 1) Visual: no qual se privilegia fotos, gráficos, folhetos e filmes; 2) Auditivo: no qual existe a preferência por debates, músicas 
etc. e 3) Cinestésico: cujo foco está na experiência física, que envolve tocar, sentir e nas atividades práticas. (GILAKJANI, 2012).

Diante desse cenário, onde cada indivíduo possui uma identidade e características próprias no processo de aquisição de conhecimento, os recursos didáticos tornam-se ferramentas indispensáveis para atender as especialidades de cada aluno, devido à diversidade de instrumentos e métodos pedagógicos, que, além de estimular o discente, podem contribuir com o desenvolvimento das aulas, enriquecendo o processo de ensino e aprendizagem (FREITAS, 2007; SANCHES et al., 2015).

Dentre os diversos tipos de recursos didáticos, o jogo é muito utilizado no ambiente escolar, por proporcionar aos discentes uma forma de ensino prazerosa, que, além do momento de descontração, promove interação, aprendizagem e socialização entre os participantes, pois as regras norteadoras dos jogos possuem um cunho pedagógico (SOUZA; RESENDE, 2016). Já a maquete ou representação cartográfica é a principal intermediária do ensino do espaço, pois esse recurso didático permite que os alunos possam transformar as representações conceituais em representações reais, contribuindo para a formação deles na interpretação crítica do espaço, além de desenvolver o cognitivo de quem constrói a maquete e de todos que observam o produto final (AZEVEDO et al., 2017).

Adicionalmente, a construção de cartilhas educativas envolve procedimentos interativos como planejamento, estruturação e pesquisa do conteúdo escolhido a ser abordado. Geralmente, a linguagem é de fácil assimilação e faz-se uso de ferramentas como imagens, desenhos e tópicos, que permitem ao público-alvo ter acesso e conhecer temas complexos, normalmente, de difícil compreensão (MORTATTI, 2000; RABELO et al., 2015). Esse também é um 
tipo de material didático bem recebido no ambiente escolar e que pode ser utilizado no processo de ensino e aprendizagem dentro e fora da sala de aula.

O uso de recursos didáticos funciona como uma peça-chave no desenvolvimento cognitivo do aluno, pois aumenta a capacidade de observação, aproxima o discente da realidade e facilita a fixação e o entendimento do conteúdo (NICOLA; PANIZ, 2016). Entretanto, não são todos os docentes que se utilizam dessas ferramentas no processo de ensino e aprendizagem, o que pode estar relacionado a falta de interesse pela novidade, falta de preparo e confiança, dificuldade em sair da zona de conforto e buscar novas ferramentas para contribuir e enriquecer o processo, ou até mesmo a falta de apoio institucional e de estrutura para a confecção de materiais didáticos alternativos (KRASILCHIK, 2004).

Diante do exposto, o presente trabalho teve como objetivo construir recursos didáticos dentro do ambiente escolar, para apresentar, de forma lúdica e interativa, informações sobre a importância e a conservação ambiental da Bacia Costeira do Sapucaia, reconhecida, em 2015, como uma nova bacia hidrográfica do Estado de Sergipe, porém ainda pouco conhecida pela população local, o que reforça a relevância do trabalho.

\section{MATERIAL E MÉTODOS}

\subsection{Bacia Costeira do Sapucaia}

O estudo teve como cenário a Bacia Costeira do Sapucaia (BCS), área que, até o ano de 2014, era considerada como pertencente ao grupo de Bacias Costeiras 1 no Estado de Sergipe (Figura 1). A BCS, constituída pelos rios Sapucaia e Aningas, possui uma área total de 118,33 km² e está localizada nos municípios 
de Japaratuba e Pirambu, região Leste do Estado de Sergipe, entre a Bacia Hidrográfica do Rio Japaratuba e do Rio São Francisco (SERGIPE, 2012; SERGIPE, 2015).

A região da BCS compreende áreas de duas Unidades de Conservação do Estado de Sergipe: (1) Reserva Biológica Santa Isabel, criada em 1988 (Decreto n. ${ }^{\circ}$ 96.999), que abrange parte dos municípios de Pirambu e Pacatuba e possui área total de 2.766 ha, sendo 45 Km de praias e (2) Área de Proteção Ambiental Litoral Norte, instituída em 2004 (Decreto n²2.995), que ocupa terras dos municípios de Pirambu, Japoatã, Pacatuba, Ilha das Flores e Brejo Grande, com área de 473,12 Km² (BRAGHINI; VILAR, 2013; GOMES et al., 2006; SERGIPE, 2015).

Figura 1 - Mapa da Bacia Costeira do Sapucaia.

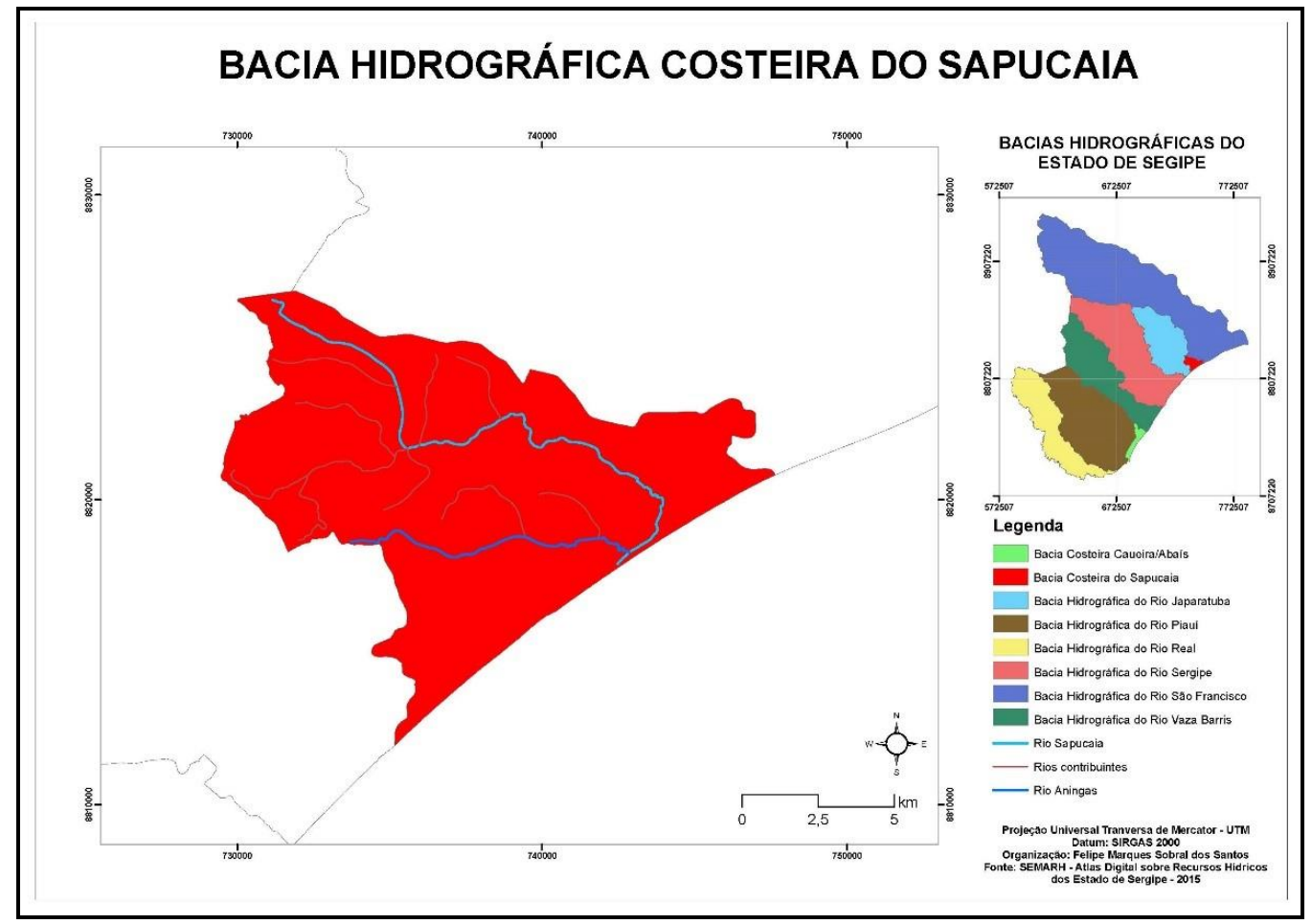

Fonte: Sergipe, 2015.

2.2 Local da pesquisa 
O trabalho foi desenvolvido no ano de 2016, em uma escola pública estadual do município de Japaratuba, Estado de Sergipe. A escola oferta as modalidades de Ensino Fundamental Regular e Educação de Jovens e Adultos, recebendo alunos das zonas urbana e rural, ambas inseridas na BCS (SERGIPE, 2017).

\subsection{Público-alvo}

As atividades foram desenvolvidas com 12 alunos do $9^{\circ}$ Ano do Ensino Fundamental, turno matutino. A turma participante foi indicada pela direção e coordenação da escola, sob a justificativa de que os alunos eram mais participativos nos trabalhos extraclasse e poderiam, por conseguinte, divulgá-los para a comunidade.

\subsection{Construção dos materiais didáticos}

Para a divulgação de informações sobre a BCS, optou-se pela confecção de três recursos didáticos, que utilizaram diferentes materiais e métodos: Jogo da Memória, Maquete e Cartilha Educativa (Quadro 1).

Antes de iniciar a confecção de cada recurso didático, ocorreram encontros entre os alunos e os pesquisadores, nos quais foi exposta a ideia da produção do material educativo e foram explanados a teoria e o método referentes ao tema e à confecção dos recursos. Após esse primeiro momento, pelo menos um pesquisador acompanhou o desenvolvimento e a construção de cada material, auxiliando na criação e ressaltando pontos relevantes dentro do tema abor dado. 
Quadro 1 - Recursos didáticos, materiais e métodos utilizados por alunos do $9^{\circ}$ ano

do Ensino Fundamental de Japaratuba, Sergipe.

\begin{tabular}{|c|c|c|}
\hline Recurso Didático & Materiais & Métodos \\
\hline Jogo da memória & $\begin{array}{l}\text { Imagens da BCS impressas } \\
\text { em papel couchê, canetas e } \\
\text { folhas A4. }\end{array}$ & $\begin{array}{l}\text { Os alunos criaram as regras do jogo, com } \\
\text { perguntas e respostas sobre cada imagem } \\
\text { da BCS. }\end{array}$ \\
\hline Maquete & $\begin{array}{l}\text { Placas de isopor, caneta, } \\
\text { estilete, tesoura, cola } \\
\text { quente, cola de isopor, } \\
\text { papel EVA (cor verde), } \\
\text { palitos de picolé, palitos de } \\
\text { dente, tinta guache (verde, } \\
\text { azul e bege) e um mapa da } \\
\text { bacia. }\end{array}$ & $\begin{array}{c}\text { Os alunos formaram três grupos e } \\
\text { dividiram as atividades de confecção } \\
\text { (desenho, recorte e montagem). Ao final, } \\
\text { todos colaboraram com a pintura da } \\
\text { maquete. }\end{array}$ \\
\hline $\begin{array}{l}\text { Cartilha } \\
\text { educativa }\end{array}$ & $\begin{array}{l}\text { Informações sobre a BCS, } \\
\text { pesquisadas pelos alunos } \\
\text { em sites, livros, trabalhos e } \\
\text { mapas da região. }\end{array}$ & $\begin{array}{l}\text { A confecção foi dividida em } 3 \text { sessões: (1) } \\
\text { Bacia Hidrográfica, com o conceito de } \\
\text { bacia e sua importância; (2) Bacia Costeira } \\
\text { do Sapucaia, que contou a história da } \\
\text { bacia, sua abrangência territorial e } \\
\text { importância local e regional e (3) } \\
\text { Impactos, apresentando os principais } \\
\text { impactos observados na área da BCS e } \\
\text { dicas para conservação. A confecção da } \\
\text { cartilha contou com a colaboração da } \\
\text { equipe de pesquisadores do projeto. }\end{array}$ \\
\hline
\end{tabular}

Fonte: Organização dos autores, 2018.

\section{RESULTADOS E DISCUSSÃO}

\subsection{Jogo da memória}

Inicialmente, foram criadas duas regras para o jogo da memória: (1) o participante que conseguir encontrar duas cartas (imagens) iguais deve responder a uma pergunta relacionada à imagem da carta e (2) se o participante errar a pergunta, deverá pagar uma prenda. Caso o erro ocorra duas vezes, o participante deverá sair do jogo.

Após a construção das regras, os alunos foram divididos em dois grupos e cada grupo recebeu cinco pares de cartas, sobre as quais foram produzidas 
perguntas e respostas. As respostas das questões foram corrigidas e complementadas pelos pesquisadores. Por fim, os alunos selecionaram algumas prendas, como "imitar um macaco" (Quadro 2; Figura 2).

Quadro 2 - Perguntas e respostas do Jogo da memória, confeccionado por alunos do $9^{\circ}$ ano do Ensino Fundamental de Japaratuba, Sergipe.

\begin{tabular}{|c|c|c|}
\hline IMAGEM & PERGUNTA & Resposta construída pelos alunos* \\
\hline 1. & $\begin{array}{l}\text { Quais os rios que formam a Bacia } \\
\text { Costeira do Sapucaia? }\end{array}$ & Rios Sapucaia e Aningas. \\
\hline 2. & $\begin{array}{l}\text { Onde está localizada a Reserva Santa } \\
\qquad \text { Isabel? }\end{array}$ & Pirambu/SE (Lagoa Redonda). \\
\hline 3. & Qual a vegetação da imagem? & Restinga \\
\hline 4. & $\begin{array}{c}\text { O que acontece com os rios quando a } \\
\text { mata ciliar é devastada? }\end{array}$ & $\begin{array}{c}\text { O processo de erosão, o qual pode cobrir } \\
\text { o rio. }\end{array}$ \\
\hline 5. & $\begin{array}{c}\text { O coqueiro é uma planta nativa ou } \\
\text { exótica? }\end{array}$ & Exótica. \\
\hline 6. & Quais são os tipos de dunas? & Móveis e permanentes. \\
\hline 7. & $\begin{array}{l}\text { Para que servem os corredores } \\
\text { ecológicos? }\end{array}$ & $\begin{array}{l}\text { Para garantir passagem dos animais de } \\
\text { um local para outro. }\end{array}$ \\
\hline 8. & $\begin{array}{l}\text { Qual a vegetação apresentada na } \\
\text { imagem? }\end{array}$ & Mangue. \\
\hline 9. & $\begin{array}{c}\text { A planta da imagem (mangueira) é } \\
\text { nativa ou exótica? }\end{array}$ & Exótica (Índia). \\
\hline 10. & $\begin{array}{l}\text { Onde está localizada essa nascente e } \\
\text { qual o nome do rio que ela origina? }\end{array}$ & $\begin{array}{c}\text { Localiza-se entre os povoados Sapucaia e } \\
\text { Porteiras e origina o Rio Sapucaia. }\end{array}$ \\
\hline
\end{tabular}

*Posteriormente corrigidas e complementadas pelos pesquisadores.

Fonte: Organização dos autores, 2018. 
Figura 2 - Jogo da memória sobre a BCS, produzido por alunos do $9^{\circ}$ ano do Ensino

Fundamental de Japaratuba, Sergipe.

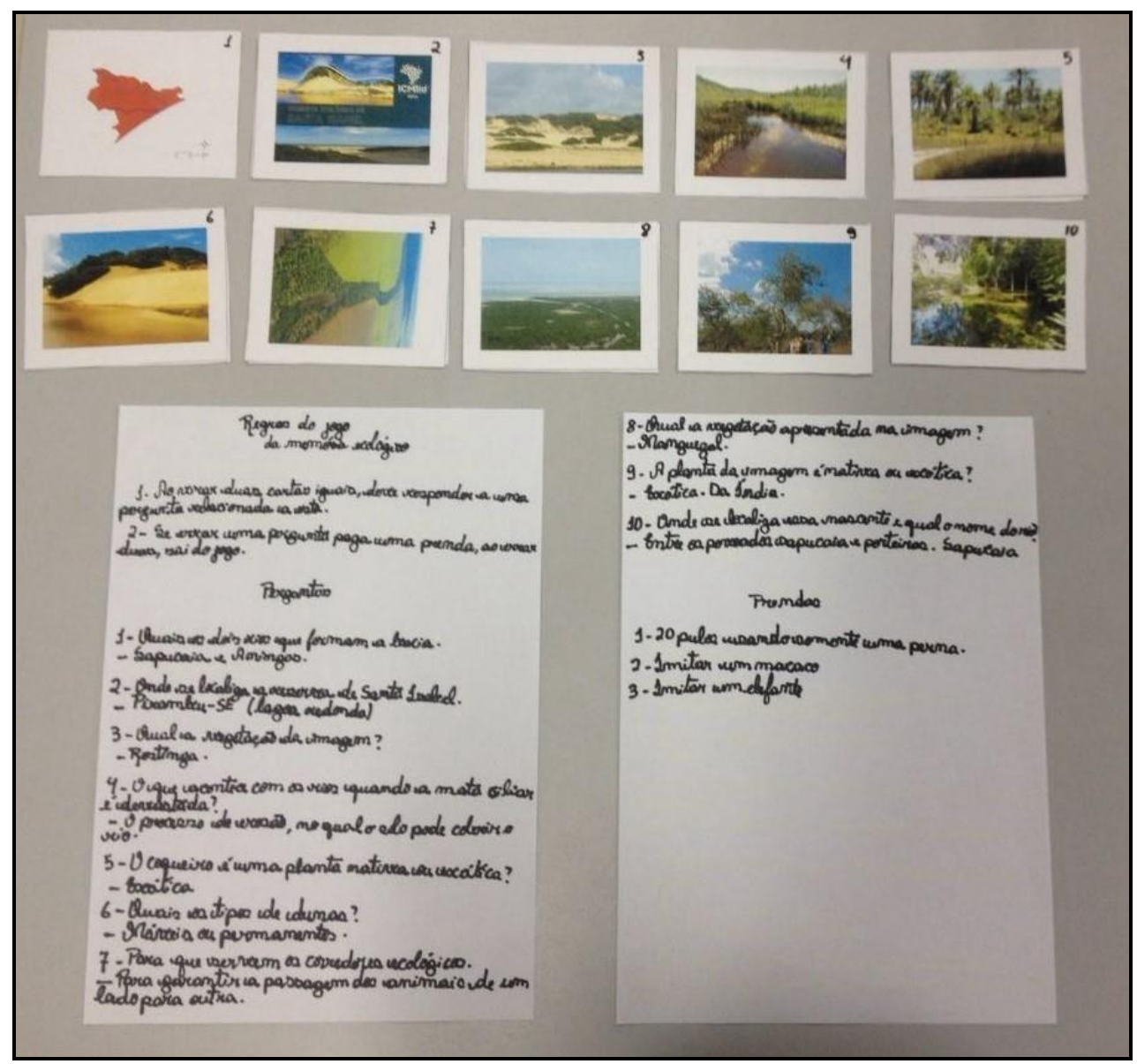

Fonte: Acervo particular dos autores (junho de 2016).

A utilização de jogos na sala de aula, quando bem estruturados, quebra o ciclo do ensino tradicional e desenvolve no aluno senso crítico, autonomia, convivência, análise dos erros, como também a convivência com as vitórias e perdas (TEIXEIRA; APRESENTAÇÃO, 2014). Segundo Silva; Mineo (2015), a introdução de jogos didáticos durante uma aula proporciona aos alunos um momento de debate, favorecendo a construção de conhecimentos sobre o tema trabalhado e proporcionando a interação professor-aluno. Tarouco et al. (2005) acrescentam a discussão sobre a utilização dos jogos didáticos como a parte prática dos assuntos teóricos abordados em sala de aula, uma vez que proporcionam um aprendizado mais lúdico, além da interação entre todos os participantes. 
A contribuição dos jogos didáticos para a melhor assimilação do conteúdo trabalhado em sala de aula se reflete, portanto, em resultados mais satisfatórios nas avaliações, como comprovam Santos; Araújo (2017), que compararam, em sua pesquisa, turmas que fizeram uso de jogos com turmas que não utilizaram esse recurso. Os resultados mostraram que as turmas que fizeram o uso de jogos didáticos acertaram 39,5\% mais questões em comparação com as turmas que não os utilizaram, sendo constatado, além disso, que as meninas tiveram maior desempenho nessas avaliações do que os meninos (SANTOS; ARAÚJO, 2017).

\subsection{Maquete}

Antes de iniciar a construção da maquete, alguns alunos levantaram questionamentos a respeito do tema, que foram sanados pelo pesquisador (Quadro 3).

Quadro 3 - Questionamentos sobre bacias hidrográficas, levantados por alunos do $9^{\circ}$ ano do Ensino Fundamental de Japaratuba, Sergipe.

\begin{tabular}{|c|c|}
\hline PERGUNTAS & RESPOSTAS \\
\hline $\begin{array}{l}\text { Como um rio pode ter um } \\
\text { tamanho grande se a sua } \\
\text { nascente é pequena? }\end{array}$ & $\begin{array}{l}\text { Um rio possui uma nascente principal, mas existem outras } \\
\text { nascentes que podem contribuir para a formação desse rio ao } \\
\text { longo do seu percurso. Desse modo, o rio é formado pela } \\
\text { junção dos cursos de água, formados por diversas nascentes. }\end{array}$ \\
\hline $\begin{array}{l}\text { Como diferenciar os } \\
\text { cursos de água que } \\
\text { formam o rio daqueles } \\
\text { que formam uma bacia? }\end{array}$ & $\begin{array}{l}\text { Uma bacia possui uma delimitação, a qual possui rios que a } \\
\text { constituem. Mas os rios podem ser divididos em três níveis: } \\
\text { 1) Rio de Primeira Ordem: onde fica localizada a nascente e o } \\
\text { curso de água é ralo; } \\
\text { 2) Rio de Segunda Ordem: é a junção de vários cursos de água } \\
\text { de Primeira Ordem; } \\
\text { 3) Rio de Terceira Ordem: é o rio principal, junção dos cursos de } \\
\text { água de Segunda Ordem. }\end{array}$ \\
\hline $\begin{array}{l}\text { Como são formadas a } \\
\text { Lagoa do Sangradouro e a } \\
\text { Lagoa Redonda? }\end{array}$ & $\begin{array}{c}\text { São formadas pelo nível do terreno. Essa área não possui muita } \\
\text { inclinação, ou seja, é um terreno mais plano. Quando a água do } \\
\text { rio chega a esse ponto, ela tende a acumular até ter força o } \\
\text { suficiente para seguir o seu curso. }\end{array}$ \\
\hline
\end{tabular}

Fonte: Organização dos autores, 2018. 
A construção da maquete da BCS iniciou-se com o primeiro grupo de alunos desenhando um modelo de mapa topográfico da BCS. Utilizou-se o mapa da bacia como base para o desenho e cada nível foi representado por uma placa de isopor. O segundo grupo colou as placas em níveis, utilizando palitos de dente e cola de isopor e o terceiro grupo confeccionou árvores para representar a flora na maquete, que, após montada, foi pintada por todos (Figura 3).

\section{Figura 3 - Construção de maquete da BCS por alunos do $9^{\circ}$ ano do Ensino}

\section{Fundamental de Japaratuba, Sergipe.}

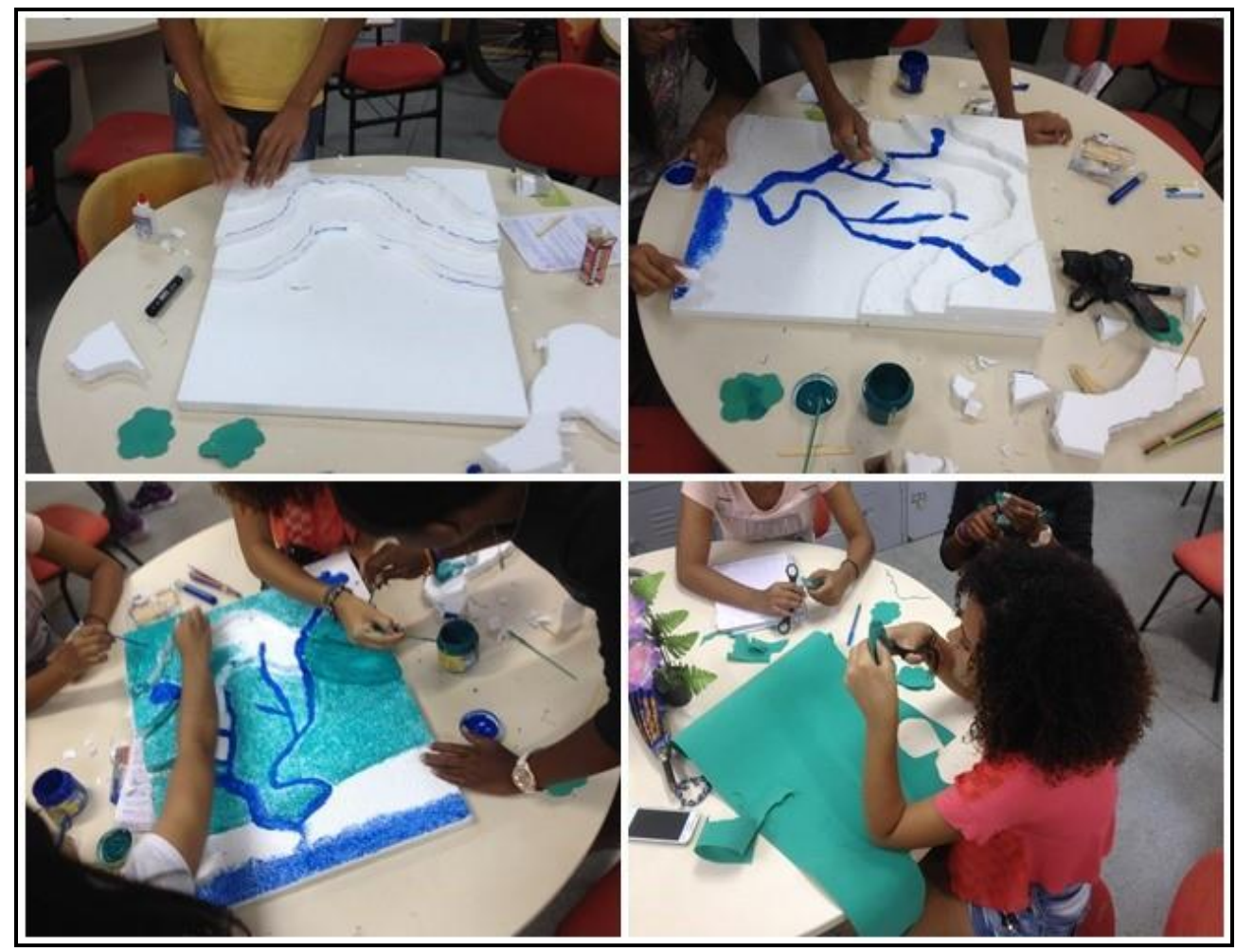

Fonte: Acervo particular dos autores (outubro de 2016).

A maquete funciona como um importante recurso didático que, devido ao seu modelo tridimensional, permite trabalhar e discutir diversos assuntos como relevo, solos, topografia e proporciona melhor entendimento dos fenômenos geográficos (DURIGAN DA LUZ; BRISKI, 2011). Para Santos et al. (2015), esse recurso didático possibilita maior interação entre professor e aluno, ampliando a compreensão do conteúdo trabalhado. 
A utilização de novas tecnologias dentro do ambiente escolar, como computadores, celulares e tabletes, vem ganhando destaque no processo de ensino-aprendizagem, entretanto, a construção de maquetes, apesar da simplicidade, ainda seduz e envolve os alunos por permitir colocar a "mão na massa" e interagir com seus colegas e professor (SANTOS et al., 2015). Segundo os autores, a maquete também pode ser uma opção de recurso didático para escolas que não possuem recursos inovadores.

No entanto, a construção de maquetes não deve se restringir somente à proposta de um produto final, e, sim, considerar cada etapa da atividade, como o planejamento, especialmente a discussão, através da são expressadas as diferentes visões, possibilitando uma construção do conhecimento mais consolidada e, finalmente, a confecção do material proposto (PELUSO; PAGNO, 2015).

Pereira et al. (2013) desenvolveram, dentro do projeto de divulgação científica GAIA (Geociências, Arte, Interdisciplinaridade e Aprendizagem), uma maquete da Serra do Espinhaço Meridional para sensibilizar tanto alunos como a comunidade e amenizar os problemas relacionados à falta de conhecimento da área e de informações locais nos livros didáticos. Os autores concluíram que essa atividade possibilitou aos discentes ampliar suas noções básicas espaciais e de conceitos importantes como localização, distribuição, proporcionalidade, escala, direcionalidade e distância.

\subsection{Cartilha educativa}

A cartilha foi dividida e construída em três sessões, tendo sido a primeira sobre Bacia Hidrográfica, abrangendo o conceito de bacia e sua importância como área que possui cursos de água que desaguam em um rio principal, localizado mais baixo em relação às nascentes, até o encontro com o mar (TUNDISI, 2013). Nessa primeira sessão, também foram destacados os serviços 
ecossistêmicos prestados pela bacia hidrográfica, como atuação no controle do clima e como corredor ecológico (CASTRO et al., 2012).

Na segunda sessão, os alunos descreveram a história da BCS e sua descoberta, com base na Resolução $n^{\circ}$ 25/2015 do Conselho Estadual de Recursos Hídricos, segundo a qual o Estado de Sergipe passa a ter oito bacias hidrográficas, ganhando duas novas bacias, chamadas de Bacia Costeira do Sapucaia e Bacia Costeira Caueira-Abaís (SERGIPE, 2016). Além da história da BCS, foram descritas também a sua abrangência territorial nos municípios de Pirambu e Japaratuba, com um total de 118,33 quilômetros quadrados, e sua importância local e regional, pois sua água abastece parte da população, além de ser utilizada nas plantações e na criação de animais (SERGIPE, 2015).

Na terceira e última etapa, os alunos apresentaram os principais impactos na BCS e dicas para sua conservação. Foram citados problemas como o lixo na água e na paisagem em volta da bacia, a pouca vegetação devido ao desmatamento, principalmente da mata ciliar, e a utilização do território para criação de gado. Para preservar a bacia, foram sugeridas atitudes como divulgação da importância do rio, não descarte de lixo nele e recolhimento do lixo encontrado, plantio de árvores e cuidados com a mata ciliar, além da solicitação de ações mais ativas do governo para cumprimento da legislação referente à proteção dos recursos hídricos, fiscalizando e promovendo a sensibilização para conservação da bacia.

Os dados levantados pelos alunos foram adequados pelos pesquisadores a uma linguagem acessível e de fácil compreensão para a cartilha, tendo sido incluídas mais duas sessões: uma sobre o Projeto, expondo as atividades realizadas, e outra sobre Água Virtual, apresentando dados sobre o volume de água gasto na produção de alimentos, roupas etc. (Figura 4). Após a impressão da cartilha, a escola recebeu exemplares para serem distribuídos aos alunos e à comunidade, além de uma versão em formato digital. 
Figura 4 - Cartilha educativa criada sobre a Bacia Costeira do Sapucaia.

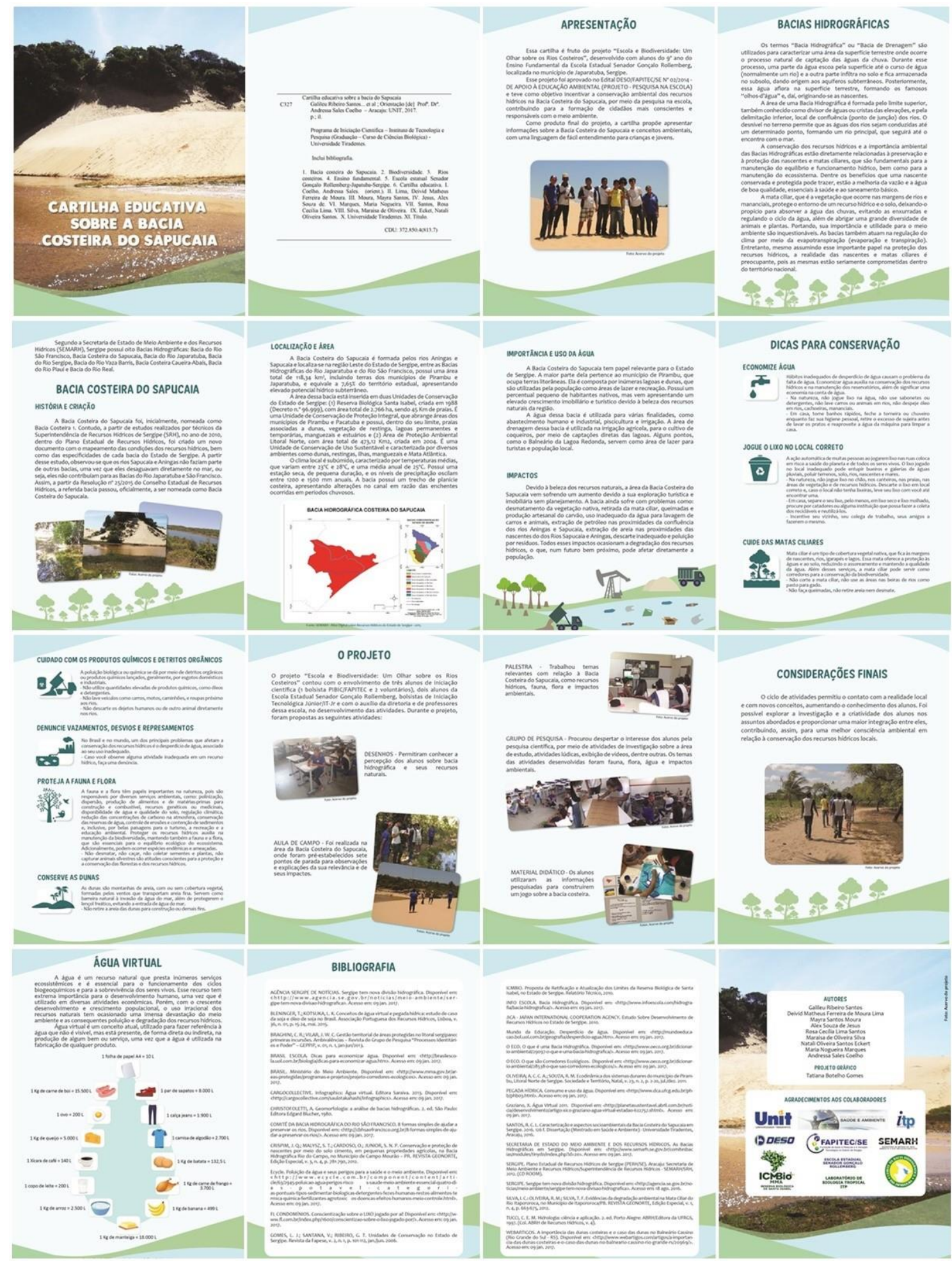

Fonte: Acervo particular dos autores (dezembro de 2016).

A construção de uma cartilha educativa passa por diversas etapas, começando pela ideia, seguida pelas primeiras pesquisas e levantamentos, esquematização e planejamento do seu conteúdo, redação, organização e 
correção do texto, desenvolvimento gráfico até a diagramação e, finalmente, impressão final. Durante esse processo construtivo, a participação e interação de todos os envolvidos possibilita abranger diversos saberes e olhares, produzindo uma cartilha rica em informações (CARVALHO, 2007; REBERTE et al., 2012).

Como possui a função de disseminar informações a respeito de um certo tema, a cartilha educativa é considerada uma importante ferramenta de Educação Ambiental, visto que, ao levar informações à população sobre um tema específico, pode sensibilizar essa população sobre os cuidados para a proteção ambiental (RABELO et al., 2015). A construção da cartilha educativa no âmbito escolar permite que as aulas sejam mais dinâmicas, pois é um recurso que contém ilustrações, fotografias, propostas de atividades, além de utilizar uma linguagem de fácil assimilação e compreensão (SENNA et al., 2012).

O uso dos recursos didáticos propicia maior participação do aluno, levando-o a refletir sobre o assunto de forma espontânea. Contudo, o docente que deseja inserir algum recurso didático, com finalidade de trabalhar os temas abordados em sala de aula, deve escolher aquele que melhor se adequa à realidade do discente, visto que a utilização desse recurso sem o devido planejamento não alcançará seu real objetivo de aprendizado (SANT'ANNA; SANT'ANNA, 2004).

Fialho (2008) discute a necessidade de o docente ter cuidado antes de levar recursos didáticos para sala de aula e cita alguns, como: (1) experimentar o recurso didático antes de levar para os discentes; (2) definir, antecipadamente, o número de grupos e/ou componentes necessários para sua realização; (2) explicar, brevemente, os temas que serão abordados no recurso, antes de iniciar a atividade; (3) no caso de jogos, verificar as regras antes de aplicar o jogo, pois o discente perde o interesse quando não compreende as regras; (4) elaborar, antecipadamente, um exercício em relação aos conteúdos abordados na atividade; (5) gerar algum tipo de recompensa que motive o aluno a participar, como uma pontuação para a atividade ou um brinde. 
A criação e utilização dos recursos didáticos como ferramentas lúdicas atende aos diversos estilos de aprendizagem, contribuindo para o processo de ensino e aprendizagem do discente, pautado na união da teoria com a prática (SILVA et al., 2017; INÁCIO et al., 2017). Carvalho et al. (2016) mencionam que a construção do conhecimento para o aluno é mais eficaz quando se trabalha o assunto em sala de aula agregado a recursos didáticos.

\section{CONCLUSÃO}

Os recursos didáticos confeccionados por alunos de uma escola em Japaratuba, Sergipe, mostraram que é possível levar ferramentas para a sala de aula utilizando-se materiais de baixo custo, além da possibilidade de trabalhar diversos conteúdos. Proporciona, também, um processo de ensino e aprendizagem focado na realidade local, fortalecendo o conhecimento do ambiente onde o indivíduo está inserido e do qual recebe influência.

A proposta das atividades foi bem recebida pelos alunos e, durante seu desenvolvimento, foi possível notar a participação espontânea e ativa deles, além do grande entusiasmo em colaborar com a construção de recursos didáticos focados numa bacia hidrográfica local, como também conhecer as funções e importância do recurso para o meio ambiente.

Por fim, acredita-se que o objetivo de confeccionar recursos didáticos e divulgar a importância e conservação da bacia foram atingidos, visto que, até então, os discentes conheciam pouco acerca da existência e da importância da BCS para a região, tampouco tinham material para trabalhar o assunto na escola.

\section{AGRADECIMENTOS}

À Universidade Tiradentes, Instituto de Tecnologia e Pesquisa, pela infraestrutura para o desenvolvimento da pesquisa. À FAPITEC/SE e Companhia de Saneamento de Sergipe (DESO), pelo apoio financeiro. À Secretaria de Meio 
Ambiente e Recursos Hídricos de Sergipe (SEMARH) e ao Comitê da Bacia Hidrográfica do Rio Japaratuba, pelo apoio logístico. À diretoria e coordenação da escola.

\section{REFERÊNCIAS}

AZEVEDO, S. C.; ARCANJO, V. M.; CARDOSO, H. J. M. Oficina de maquete: a busca por um aprofundamento do processo ensino-aprendizagem. Revista Brasileira de Educação em Geografia, Campinas, vol. 7, n. 14, p. 287-297, 2017.

BALBINOT, R.; OLIVEIRA, N. K.; VANZETTO, S. C.; PEDROSO, K.; VALERIO, Á. F. O papel da floresta no ciclo hidrológico em bacias hidrográficas. Ambiência, Guarapuava, vol.4, n.1, p. 131-149, 2008.

BARRETO, S. R.; RIBEIRO, S. A.; BORBA, M. P. Nascentes do Brasil: estratégias para a proteção de cabeceiras em bacias hidrográficas. São Paulo: WWF-Brasil, 2010.

BRAGHINI, C. R.; VILAR, J. W. C. Gestão territorial de áreas protegidas no litoral: primeiras incursões. Ambivalências, São Cristóvão, vol. 1, p. 1-14, 2013.

BRASIL. Lei N. ${ }^{0} 9.795$ de 27 de abril de 1999. Dispõe sobre a educação ambiental, institui a Política Nacional de Educação Ambiental e dá outras providências. Diário Oficial da República Federativa do Brasil, Brasília, n. 79, 28 abr. 1999.

Lei $\mathbf{N}^{0}$ 12.651, de 25 de maio de 2012. Dispõe sobre a proteção da vegetação nativa; altera as Leis no 6.938, de 31 de agosto de 1981, 9.393, de 19 de dezembro de 1996, e 11.428, de 22 de dezembro de 2006; revoga as Leis no 4.771, de 15 de setembro de 1965, e 7.754, de 14 de abril de 1989, e a Medida Provisória no 2.166-67, de 24 de agosto de 2001; e dá outras providências. Diário Oficial da União, Brasília, n. 102, 28 mai. 2012 a.

Resolução n. 2, de 15 de junho de 2012. Estabelece as Diretrizes Curriculares Nacionais para a Educação Ambiental. Diário Oficial da União, Brasília, n. 116, seção 1, p. 70,18 jun. 2012 b.

CARVALHO, F. A. H. Reaprender a aprender: a pesquisa como alternativa metacognitiva. 2007. 152p. Tese (Doutorado em Educação) - Pontifícia Universidade Católica do Rio Grande do Sul, Porto Alegre.

CARVALHO, J. W. L. T.; MYSCZAK, L. A.; OLIVEIRA, F. A. Bacias hidrográficas simuladas em maquetes: prática pedagógica para ensino fundamental e médio. Geosaberes, Fortaleza, vol. 7, n. 13, p. 25-39, 2016. 
CASTRO, D.; MELLO, R. S. P.; POESTER, G. C. Práticas para restauração da mata ciliar. Porto Alegre: Catarse - Coletivo de Comunicação, 2012.

DURIGAN DA LUZ, R. M.; BRISKI, S. J. Aplicação didática para o ensino da geografia através da construção e utilização de maquetes. Revista Geográfica de América Central, Heredia, vol. 2, n. 47E, p. 1-20, 2011.

FIALHO, N. N. Os jogos pedagógicos como ferramentas de ensino. In: VIII CONGRESSO NACIONAL DE EDUCAÇÃO, Curitiba. Anais... Curitiba: Pontifícia Universidade Católica do Paraná, 2008. p. 12298-12306.

FREITAS, O. Equipamentos e materiais didáticos. Brasília: Universidade de Brasília, 2007.

GILAKJANI, P. A. A Match or Mismatch Between Learning Styles of the Learners and Teaching Styles of the Teachers. Modern Education and Computer Science, ed. 11, p. 51-60, 2012.

GÓIS, J. S.; MENDES, L. E. Hidrologia e hidrometria. In: TELLES, D. D. (Org.). Ciclo ambiental da água: da chuva à gestão. São Paulo: Blucher, 2013. p. 55-76.

GOMES, L. J.; SANTANA, V.; RIBEIRO, G. T. Unidades de Conservação no Estado de Sergipe. Revista da Fapese, Aracaju, vol. 2, n. 1, p. 101-112, 2006.

INÁCIO, F. F.; OLIVEIRA, K. L.; MARIANO, M. L. S. Estilos intelectuais e estratégias de aprendizagem: percepção de professores do ensino fundamental. Psicol. Esc. Educ., Maringá, vol. 21, n. 3, p. 447-455, dez. 2017.

KLEIN, A. M.; PÁTARO, C. S. O. A escola frente às novas demandas sociais: educação comunitária e formação para a cidadania. Cordis: Revista Eletrônica de História Social da Cidade, São Paulo, vol. 1, p. 1-8, 2008.

KRASILCHIK, M. Prática de ensino de Biologia. 4. ed. São Paulo: Edusp, 2004.

LIMA, J. R. O desafio da escola em trabalhar com a diversidade. Revista Memento, Vale do Rio Verde, vol. 3, n. 1, jan.-jul. 2012.

MACHADO, L. C.; SELVA, V. S. F.; SANTOS, S. M. Proposta metodológica interdisciplinar como ferramenta para o potencial de conservação de nascentes. Journal of Environmental Analysis and Progress, Recife, vol. 3, n. 1, p. 8-23, 2018.

MORTATTI, M. R. L. Cartilha de alfabetização e cultura escolar: um pacto secular. Cad. CEDES, Campinas, vol. 20, n. 52, p. 41-54, 2000.

NICOLA, J. A.; PANIZ, C. M. A importância da utilização de diferentes recursos didáticos no ensino de biologia. Infor, Inov. Form., Rev. NEaD-Unesp, São Paulo, vol. 2, n. 1, p. 355-381, 2016. 
OLIVEIRA, K. L.; SANTOS A. A. A.; SCACCHETTI, F. A. P. Medida de estilos de aprendizagem para o ensino fundamental. Psicologia Escolar e Educacional, São Paulo, vol. 20, n. 1, p. 127-136, 2016.

OLIVEIRA, T.; VIANA, A. P. S.; BOVETO, L.; SARACHE, M. V. Escola, conhecimento e formação de pessoas: considerações históricas. Políticas Educativas, Porto Alegre, vol. 6, n. 2, p. 145-160, 2013.

PEÇANHA, M. P.; FREITAS, N. P. Biodiversidade em ambiente de água doce. In: TELLES, D. D. (Org.). Ciclo ambiental da água: da chuva à gestão. São Paulo: Blucher, 2013. p. 77-92.

PELUSO, D.; PAGNO, F. O uso de maquetes como recurso didático. In: SEMINÁRIO NACIONAL INTERDISCIPLINAR EM EXPERIÊNCIAS EDUCATIVAS, Francisco Beltrão. Anais... Francisco Beltrão: Universidade Estadual do Oeste do Paraná, 2015. p. 795805.

PEREIRA, M. V. P.; MACEDO, C. S.; PIUZANA, D.; MORAIS, M. S. A comunicação através da arte: construção da maquete da Serra do Espinhaço Meridional como recurso interdisciplinar e didático. TerritoriumTerram, São João del-Rei, vol. 1, n. 2, p. 65-80, 2013.

POSTEL, S. L.; THOMPSON JR., B. H. Watershed protection: capturing the benefits of nature's water supply services. Natural Resources Forum, vol. 29, p. 98-108, 2005.

RABELO, R. C.; GUTJAHR, A. L. N.; HARADA, A. Y. Metodologia do processo de elaboração da cartilha educativa "O papel das formigas na natureza". Enciclopédia Biosfera, Goiânia, vol.11, n. 21, p. 2769-2777, 2015.

REBERTE, L. M.; HOGA, L. A. K.; GOMES, A. L. Z. O processo de construção de material educativo para a promoção da saúde da gestante. Revista Latino-Americana de Enfermagem, Ribeirão Preto, vol. 20, n. 1, p. 101-108, 2012.

SANCHES, C. C.; PERIÇATO, A. J.; MANSANO, C. N. A criação e utilização de diferentes recursos didáticos aplicados à geografia para o ensino fundamental. Revista Científica ANAP Brasil, Tupã, vol. 8, n. 10, p. 26-40, 2015.

SANT'ANNA, I. M.; SANT'ANNA, V. M. Recursos educacionais para o ensino: quando e por quê?. Petrópolis: Vozes, 2004.

SANTOS, A. G.; SANTOS C. A. P. A inserção da educação ambiental no currículo escolar. Remoa: Revista Monografias Ambientais, Santa Maria, vol. 15, n. 1, p. 369380, 2016.

SANTOS, A. V.; ARAÚJO, F. B. Utilização de jogo didático para o ensino de tabela periódica. Revista Eletrônica LudusScientiae, Goiânia, vol. 1, n. 2, p. 78-89, 2017. 
SANTOS, M. S.; DUARTE, G. S.; ROSA, O. O uso de maquetes no ensino aprendizagem em geografia. Enciclopédia Biosfera, Goiânia, vol. 11, n. 20, p. 620-625, 2015.

SENNA, S. N.; SILVA, M. V; VIEIRA, M. R. Uso de cartilha com atividades lúdicas como material complementar para o ensino e aprendizagem de doenças parasitárias. In: ENCONTRO DE CIÊNCIAS DA VIDA, Ilha Solteira. Anais... Ilha Solteira: Universidade Estadual Paulista, 2012. p. 1-4.

SERGIPE. Secretaria de Estado do Meio Ambiente e dos Recursos Hídricos. Plano estadual de recursos hídricos de Sergipe. Aracaju: Semarh/SRH, 2012. (CD ROM).

Secretaria de Estado do Meio Ambiente e dos Recursos Hídricos. Atlas de Recursos Hídricos. Aracaju: Semarh/SRH, 2015 (Pen card).

Secretaria de Estado do Meio Ambiente e dos Recursos Hídricos. Conselho Estadual de Recursos Hídricos. Resolução n 27 de 2015. Diário Oficial Estado de Sergipe. Aracaju, SE, p. 3-4, abr. 2016.

Secretaria de Estado da Educação. Rede Estadual: Escola Estadual Senador Gonçalo Rollemberg, $2017 . \quad$ Disponível em: <http://www.seed.se.gov.br/redeestadual/Escola.asp?cdescola=228\&cdestrutura=343 >. Acesso em: 11 mai. 2018.

SILVA, A. C. M.; FREITAG, I. H.; TOMASELLI, M. V. F.; BARBOSA, C. P. A importância dos recursos didáticos para o processo ensino-aprendizagem. Arquivos do MUDI, Maringá, vol. 21, n. 2, p. 20-31, 2017.

SILVA, N.; MINEO, M. F. Elaboração e aplicação do jogo ambiental como instrumento de educação ambiental. Revista Eletrônica em Gestão, Educação e Tecnologia Ambiental, Santa Maria, vol. 19, n. 2, p. 1078-1082, 2015.

SODRÉ, F. F. Fontes Difusas de Poluição da Água: Características e métodos de controle. Artigos Temáticos do AQQUA, Brasília, vol. 9, p. 9-16, 2012.

SOUZA, I. A.; RESENDE, T. R. P. S. Jogos como recurso didático-pedagógico para o ensino de Biologia. Scientia cum Industria, Caxias do Sul, vol. 4, n. 4, p. 181-183, 2016.

TAROUCO, L. M. R.; KONRATH, M. L. P.; GRANDO, A. R. S. O aluno como coconstrutor e desenvolvedor de jogos educacionais. Revista Novas Tecnologias na Educação, Porto Alegre, vol. 3, n. 2, p. 1-8, 2005.

TEIXEIRA, R. R. P.; APRESENTAÇÃO, K. R. S. Jogos em sala de aula e seus benefícios para a aprendizagem da matemática. Revista Linhas, Florianópolis, vol. 15, n. 28, p. 302-323, 2014. 
TELLES, D. D. A água e o ambiente. In: TELLES, D. D. (Org.). Ciclo ambiental da água: da chuva à gestão. São Paulo: Blucher, 2013. p. 27-54.

TEODORO, V. L. I.; TEIXEIRA, D.; COSTA, D. J. L.; FULLER, B. B. O conceito de bacia hidrográfica e a importância da caracterização morfométrica para o entendimento da dinâmica ambiental local. Revista Uniara, vol. 11, n. 1, 2007.

TUCCI, C. E. M.; MENDES, C. A. Avaliação Ambiental Integrada de Bacias Hidrográficas. Ministério do Meio Ambiente; Programa das Nações Unidas para o Desenvolvimento. Brasília-DF. 2006. 362p.

TUNDISI, J. G. A governança da água. Rev. UFMG, Belo Horizonte, vol. 20, p. 222-235, 2013. 